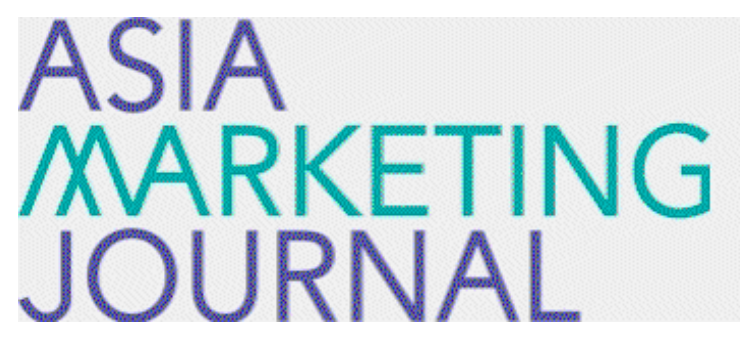

ASIA MARKETING JOURNAL

Volume 14 | Issue 1

Article 7

4-30-2012

\title{
전환 좌절상황에서 소비자의 부정적 심리반음에 관한 연구
}

Yun Hee Jeong

Follow this and additional works at: https://amj.kma.re.kr/journal

Part of the Marketing Commons

\section{Recommended Citation}

Jeong, Yun Hee (2012) "전환 좌절상황에서 소비자의 부정적 심리반을 에 관한 연구," Asia Marketing Journal: Vol. 14 : Iss. 1 , Article 7.

Available at: https://doi.org/10.53728/2765-6500.1475

This Article is brought to you for free and open access by Asia Marketing Journal. It has been accepted for inclusion in Asia Marketing Journal by an authorized editor of Asia Marketing Journal. 


\title{
전환 좌절상황에서 소비자의 부정적 심리반응에 관한 연구*
}

\author{
The Effects of Switching-Frustrated Situation \\ on Negative Psychological Response
}

정 윤 희(Jeong, Yun Hee)**

현재 치열한 경쟁상황 속에서 기업들은 소비자들이 다른 대안으로 전환하는 것을 막기 위한 다양 한 전략들을 실행하고 있으며, 이 중에서 전환장벽을 이용하는 전략은 고객유지와 관련해 매우 효과 적인 것으로 알려져 있다. 하지만 전환 장벽으로 인해 새로운 대안으로 바꾸지 못하고 현재 서비스 제공자와의 관계를 유지해야 하는 소비자 입장에서도 전환장벽이 긍정적일 것인가?

심리적 반작용이론에 의하면, 사람들은 어떤 자유가 위협받거나 제거될 때, 그 자유를 되찾는 방향 으로 동기부여 되거나 어떤 부정적 반응을 보일 수 있다고 하였다. 전환장벽 역시 전환의 자유를 제 약한다는 점에서 소비자의 부정적 반응을 유발할 수 있으므로, 본 연구는 전환장벽으로 인해 다른 대 안을 단념해야 하는 상황에서 소비자가 경험할 수 있는 부정적 심리 반응과 그에 영향을 주는 변수 들에 초점을 맞춘다.

연구가설에서, 부정적 심리반응에는 '이전선택에 대한 후회', '현재 제공자에 대한 원망', '좌절된 제 공자에 대한 열망'을 포함하였으며, 전환좌절 상황의 특성-'좌절된 대안의 매력성', '전환 장벽의 심각 성'-이 이러한 반응들에 영향을 줄 것으로 가정하였다. 그리고 이러한 전환 좌절상황의 특성이 주는 부정적 영향은 현재까지 해당 제공자로부터 받은 대우에 따라서 달라질 것으로 보고 지각된 공정성 을 조절변수로 추가하였다. 연구 결과 전환좌절상황의 특성과 부정적 심리반응의 관계는 모두 지지된 반면, 지각된 공정성의 조절효과는 대부분의 관계를 상호작용 공정성이 조절하는 것으로 나타나 일부 만이 지지 되었다. 이러한 결과는 전환 장벽의 긍정적 측면에만 영향을 밝혀온 기존 연구의 한계점 보완하고 있으며 그에 따른 이론적 실무적 시사점을 제공해준다.

핵심개념: 전환좌절상황, 전환장벽, 후회, 원망, 열망, 공정성

* 이 논문은 2012 학년도 건국대학교 학술진홍연구비 지원에 의한 논문임.

- 논문에 대해 소중한 제언을 해주신 심사위원분들께 깊이 감사드립니다.-

** 건국대학교 글로컬 캠퍼스 경영학과 조교수(yunhee0222@kku,ac.kr) 


\section{I. 서 론}

현재 치열한 경쟁 속에서 많은 기업들은 고객 들이 다른 기업으로 전환하지 못하도록 하는 다양한 장치들을 마련하고 있다. 예를 들어, 의 무 계약기간을 조건으로 초기 할인혜택이나 사 은품을 제공하면서 이를 위반하고 다른 기업으 로 전환할 때 위약금을 지불하도록 함으로써 다 른 기업으로 갈 수 없도록 묶어두기도 한다.

그렇다면 고객의 입장에서 이렇게 묶여 있는 기간 중 마음에 드는 대안을 만난다면 어떨까? 물론 어떤 고객들은 계약기간 동안 아예 다른 대안을 고려하지 않고 의도적으로 회피하기도 하겠지만, 대다수 고객들은 계약 기간 중이라도 전환하고 싶은 욕구를 가질 것이다. 하지만 계 약을 파기할 경우 어떤 금전적 손해를 겪을 수 있기 때문에 마음에 드는 대안이라 하더라도 그 대안을 포기한 채 현재 기업과의 관계를 지속 해야 하는 상황이 일어날 수 있다. 본 연구에서 는 이러한 상황을 전환 좌절상황이라고 하고 이 부분에 초점을 맞춰서 연구를 진행하였다. 좌절이란 마음이나 기운이 꺾임을 의미하는 것 으로 어떤 외부적 영향에 의해 영향을 받아 원 하는 바를 못하게 됨을 내포하는 말로서, 어쩔 수 없다는 수동성을 강조하고 있는 용어이다. 다시 말해, 전환의 좌절이란 어떤 소비자가 다 른 대안적 서비스로 바꾸는 것을 고려하다가 어떤 제약을 인지하고(예를 들어 전환할 경우 지불해야 하는 위약금을 떠올리거나 혹은 기존 에 서비스 제공자와 거래하면서 쌓아둔 마일리 지를 버려야 함을 떠올리는 경우) 어쩔 수 없 이 마음을 돌리는 경우라고 할 수 있다. 이는
시장에 많은 대안들이 소비자들을 끊임없이 유 혹하고, 그런 상황 속에서 제공자들은 소비자들 이 다른 대안으로 바꾸지 못하도록 다양한 전 환장벽을 이용한다는 점을 고려할 때, 전환 좌 절 상황은 아주 흔히 일어날 수 있는 상황이라 고 할 수 있다.

이러한 전환이 좌절되는 상황에서 소비자들은 결국에 전환을 하지 못하고 기업과의 관계를 유지할 가능성이 높아지기 때문에, 기업입장에 서는 긍정적일 수 있다. 이러한 이유에서 기존 연구들도 전환장벽이 소비자의 전환의지를 껶 고 기업과의 관계를 유지하게 하는 부분을 주 로 강조하고 있다(Colgate and Lang 2001). 하 지만 전환의지가 껵인 고객의 입장에서 볼 때 전환장벽은 부정적 요소가 될 가능성이 있으며. 기존 연구에서도 기업이 고객을 묶어두기 위해 의도적으로 설정한 장벽들이 장기적으로 해로 울 수 있음이 논의되기 시작하였다(Jones et al. 2000). 사실 전환장벽으로 인한 전환의 좌절은 고객의 입장에서 내면적으로 부정적인 반응이 발생할 수도 있을 것이다. 예를 들어 반작용이 론(Brehm et al 1966: Lessne 1987)에 의하면, 사람들은 본인의 어떤 자유가 위협받을 때 분 노할 수 있으며 또한 가지지 못하는 대안을 더 바라게 될 수도 있기 때문에, 소비자들은 장벽 으로 인해 원하는 일(새로운 대안으로의 전환) 을 하지 못할 때, 그 일(새로운 대안)에 대한 갈망이 더 강해지거나, 좌절을 일으킨 제공자에 대한 부정적 감정을 보여줄 수도 있을 것이다.

따라서 본 연구는 전환장벽의 긍정적 영향에 만 초점을 맞추고 있는 기존 연구의 한계점을 보완하고, 전환상황에 대한 새로운 시각을 제시 하고자, 전환장벽이 고객의 전환의지를 꺾음으 
로써 기업에 가져오는 표면적인 관계유지의 결 과가 아니라, 전환을 방해받은 소비자의 입장에 서 유발될 수 있는 내면적인 부정적 결과에 초 점을 맞추어 연구를 진행하고자 한다. 이러한 연구방향에 따른 구체적인 연구목적은 다음과 같다.

첫째, 전환장벽의 방해로 전환의지가 꺾인 '전 환좌절 상황에서 소비자가 경험할 수 있는 부 정적 심리반응에는 무엇이 있는지를 제안할 것 이다. 지금까지 전환 장벽에 관한 연구들이 다 양한 방향에서 진행되었지만, 표면적인 관계유 지에만 초점을 맞춘데 반해, 본 연구는 전환을 방해받은 소비자의 입장에서 접근함으로써, 전 환 장벽의 잠재적인 부정적 결과를 보여주고자 한다.

둘째, 부정적 심리반응의 제안과 더불어, 이런 반응들에 영향을 주는 전환 좌절 상황의 특성 들을 제시할 것이다. 즉 전환장벽으로 인해 전 환의 의지가 꺾인(좌절된) 상황에서 어떤 특성 들이 특히 부정적 반응들을 더 이끌 것인가를 보여주고자 한다.

셋째, 전환좌절 상황에서의 부정적 결과들을 밝히되, 이러한 부정적 결과를 경감시킬 수 있 는 어떤 조절변수도 함께 제안할 것이다. 이를 통해 이론적 실무적 시사점을 확장하고, 전환좌 절상황에 대한 설명력을 높일 것이다.

본 연구는 이러한 세 가지 연구목적을 통해 궁극적으로는 전환장벽이 가져올 수 있는 긍정 적 영향을 넘어 내면에 심리적으로 작용할 수 있는 부정적 측면을 구체적으로 보여줌으로써 전환장벽에 대한 시각을 넓히고자 한다.

\section{II. 이론적 배경}

\section{1 전환장벽에 관한 연구들}

전환이란 어떤 대안에서 다른 대안으로 옮겨 가는 것으로서, 현재 시장 상황 속에서 전환은 고객들에게 매우 빈번하게 일어나고 있다. 고객 들은 원래 거래하는 제공자에 대한 불만족이나 어떤 실패상황 때문에 제공자를 바꾸기도 하고, 심지어 만족하더라도 다른 매력적인 대안을 발 견했거나 혹은 개인적인 성격이나 다른 이유로 제공자를 바꾸기도 한다. 이러한 고객의 전환 및 이탈과 관련된 요인을 찾는 것은 기업의 수 익과 직결되는 중요한 문제이기 때문에 현재까 지 많은 관련 연구들이 진행되었다.

특히 고객만족은 고객이 다른 대안으로 전환 하지 않고 장기적 관계를 구축하고 유지하는 부 분에 있어서 중요한 선행요인인 것으로 밝혀졌 다. 그러나 만족한 모든 고객들이 충성도를 보 이는 것은 아니며(Oliva et al. 1992), 또한 불 만족한 모든 고객들이 공급자와의 관계를 깨지 는 않는다(Jones and Sasser 1995). 이는 만족 과 불만족을 넘어서는 서비스 전환의 다른 원 인이 존재함을 보여주며, 전환장벽은 고객들이 심각하게 전환을 고려할 때조차도 현재 제공자 와의 관계를 유지하기로 하는 이유를 잘 설명하 는 것으로 나타났다(Colgate and Lang 2001). 전환장벽은 "고객이 제공자를 바꾸는 데 있어 더 어렵거나 비용적으로 만드는 어떤 요인"으로 개념화 되며(Jones et al. 2000), 현재까지 많은 연구들에서 재구매(혹은 재방문) 행동과 연결 되는 것으로 밝혀졌다(Burnham et al. 2003). 
즉 전환장벽은 고객들이 심지어 만족함에도 불 구하고 다른 대안으로 전환하는 상황에서 고객 들을 기업에 고착시키는 방안으로서 중요하게 부각되고 있다.

이러한 전환장벽 중에서는 탐색비용 같이 개 인적으로 만들어지는 장벽도 있지만, 로열티프 로그램이나 약정과 같이 기업이 의도적으로 만 드는 것들도 존재한다. 하지만, 기업이 고객을 묶어두기 위해 의도적으로 설정한 장벽들이 장 기적으로 해로울 수 있음이 논의되고 있으며 (Jones et al. 2000), 강압적인 것으로서 지각되는 전환장벽(e.g., 재무적 전환 비용)은 '부정적 전 환장벽'으로 분류될 수도 있다고 하였다(Egan 2001). 즉 전환장벽은 장벽이라는 의미가 가지 는 것처럼, 무언가를 못하게 하고 방해한다는 측면에서 소비자들의 부정적 반응을 이끌 수 있음에도 불구하고 이러한 부분을 설명한 연구 는 거의 없다.

따라서 본 연구에서는 다음의 장벽에 관한 연 구를 근거로 전환장벽의 표면적인 긍정적 반응 (재구매 혹은 재방문, 관계 유지)이 아니라 소 비자 내면에서 발생할 수 있는 부정적 반응을 밝히고자 한다. 그리고 이를 위해 전환장벽에 대한 연구를 진행함에 있어, 전환장벽의 개별 유형(e.g., 탐색비용, 관계효용)을 연구 단위로 하기 보다는, '제공자를 바꾸는 것을 어렵게 혹 은 비용적으로 만드는 요인(Jones et al. 2000)' 이라는 전환장벽의 일반적이고 포괄적인 개념 측면에서 접근함으로써 차후에 다양한 유형의 전환장벽에 대해 적용할 수 있는 가능성을 열 어두고자 한다.

\section{2 장벽에 대한 반응에 관한 연구}

Lewin(1935)은 '장벽'을 어떤 목적 달성을 위 한 진행을 방해하거나 어렵게 하는 것으로 설명 하고 있다. 예를 들어 장벽은 인형을 가지러 가 는 아이의 길을 막는 의자와 같이, 실질적인 물 건일 수도 있고, 어떤 활동 권한을 제한하는 것 이나 혹은 과업의 복잡성도 될 수 있다(Lewin 1935). 이러한 장벽은 어떤 대상에 대한 물리적 혹은 심리적 접근성을 떨어뜨림으로써 그것을 어렵게 하거나 못하게 만들기 때문에(정윤희와 이종호 2010), 장벽의 가장 큰 영향은 하는 일 을 그르치게 하거나 혹은 시도조차 하지 않고 단념하게 만드는 것이라고 말할 수 있다.

하지만 정윤희와 이종호(2010)에 따르면, 사람 들은 장벽에 의해 의지를 꺾을 뿐 아니라, 심리 적으로는 더 동기부여되거나 장벽에 대한 부정 적 반응을 보일 수도 있다는 것이다. 이렇듯 장 벽이 어떤 선택의 자유를 제약하거나 방해할 때, 심리적으로는 다양한 반응들이 일어날 수 있는데, 이를 설명하는 것이 심리적 반작용이론 이다.

반작용 이론(reactance theory)은 사람들이 선 택의 자유가 제한될 때 어떻게 반응하는지를 설 명하는 사회 심리적 이론이다. 이 이론에 따르면, 사람들은 어떤 일을 자유롭게 하지 못할 때, 제 약 받는 대상에 대해 심리적으로 더 끌려하거 나 제약 받는 상황에 반발할 수 있다(Brehm 1966: Brehm and Brehm 1981; Clee and Wicklund 1980; Hammock and Brehm 1966: Henion and Batsell 1976). 즉 사람들은 특정행 동을 하는 데 대한 개인의 자유가 위협받을 때, 위협을 받은 행동이 더 매력적으로 되거나 위 
협을 하는 원천에 대해 부정적 반응을 보일 수 있다는 것으로, 어떤 장벽에 의해 의사결정을 방해 받는 소비자(부분적 혹은 전체적으로)는 점차 그 대안을 획득하고자 동기부여 될 것이 라고 하였다(Clee and Wicklund 1980, p. 393). 예를 들어, Lewin(1935)은 아이들이 그들이 자유롭게 움직이는 것을 방해하는 어른들의 금 지나 명령에 대해서 반발하여 어떤 행동에 대 해 심리적으로 동기부여 될 수 있다고 하였으 며, 또한 Clee와 Wicklund(1980)도 의사결정 대 안이 장벽에 의해 방해받을 때 당장은 하기 어 려울 지라도 그 대안을 획득하도록 점차 심리 적으로 동기부여 된다고 하였다. 예를 들어 정 윤희와 이종호(2010)는 소비자들이 어떤 경험을 하고자 할 때 직면하는 다양한 장벽들(예를 들 어, 시간의 제한이나 기술 습득의 어려움, 필요 한 장비의 가격 등)이 해당 경험을 하기 힘들 게 만들기도 하지만, 한편으로 그 경험을 더 기 대하고 선망하게 함으로써 더 하도록 동기부여 하는 역할도 함을 보여주었다. 그리고 광고분야 연구에서는 소비자들이 강압적인 광고메시지에 대한 반작용으로, 인지적 감정적인 반응, 즉 광 고메시지의 원천을 비난하거나 반대의 주장을 하게 된다거나 화를 내는 등의 반응이 일어날 수 있다고 하였다(Dillard and Shen 2005).

전환장벽의 영향 역시 유사한 방향에서 나타 날 수 있을 것이다. 전환장벽 역시 고객들이 다 른 대안으로 전환하는 것을 막기도 하지만, 한 편으로 더 전환하고 싶도록 동기부여하거나 부 정적 심리 반응을 이끄는 다른 측면도 가질 수 있을 것이다.

\subsection{1 전환좌절 상황에서 발생가능한 부정적 심리반응}

본 연구에서는 세 가지 부분에 있어서의 부정 적 심리반응을 제안하고 있다. 즉. '내가 했던 선택에 대한', '현재 제공자에 대한', '좌절된 대 안에 대한 부정적 심리반응을 포함한다. 이 세 가지 부분에서의 부정적 심리반응을 제안하기 위해, 다음의 두 가지 방향에서 접근하였다.

먼저 전환좌절 상황 역시 전환을 하지 못하는 전환 실패 상황이 될 수 있다는 것이다. 다만 전환장벽은 내가 자율적으로 이전에 선택했던 부분(예를 들어 서비스 가입 당시 어떤 혜택을 받기 위해 계약 기간 등을 자율적으로 선택)으 로 인해 전환이 어려운 상황일 가능성이 높기 때문에 기업의 잘못이라기보다는 어느 정도 나 의 탓으로 귀인하는 실패상황이라는 점에서 차 이가 있다. 그래서 서비스 실패와 관련성이 있 되 내 선택에 귀인 하는 감정인 '후회'를 이전 선택에 대한 부정적 심리반응으로 포함하였다.

그리고 다른 하나의 접근방식은 전환좌절 상 황이 전환의 자유를 제약받는 상황의 하나이기 때문에 반작용이론이 적용될 수 있다는 것이다. 반작용이론에 따르면 어떤 자유를 제약받을 때 이용가능하지 않은 대안의 매력성 증가. 그리고 분노 등을 표출할 수 있다고 하였는데, 이를 참 조하되 전환 좌절 상황이라는 점을 반영하여 '현재 제공자에 대한 원망'과 '좌절된 제공자에 대한 열망을 포함하였다.

\subsubsection{1 이전 선택에 대한 후회}

어떤 소비자의 의사결정이나 선택결과와 관련 된 부정적 감정으로는 실망과 후회가 자주 언 
급되었다(Zeelenberg and Pieters 1999), 여기 에서 실망은 어떤 제품을 선택하고 나서 기대 했던 긍정적 결과가 발생하지 않은 것에 따른 부정적 감정인 반면, 후회는 다른 선택을 했더 라면 더 좋은 결과가 있었을 것이라는 생각에 따른 부정적 감정을 가리킨다(Landman 1993: Zeelenberg, van Dijk, Manstead, and van der Pligt 2000), 본 연구에서 전환좌절 상황의 경 우는 현재 거래하는 제공자가 약속을 지키지 않아 소비자가 생각했던 바와 달라서 발생한 것이 아니라. 본인의 이전 선택으로 인해 다른 새로운 대안으로 자유롭게 바꾸지 못하는 상황 이기 때문에 이런 상황을 초래한 본인의 이전 선택을 후회할 가능성이 있다. 특히 후회가 부 정적 선택결과를 자신의 탓으로 귀인할 때 유발 되는 감정이고(Frijida, Kuipers, and ter Schure 1989), 기업이 설정한 전환장벽 대부분이 계약 당시 소비자가 인정하고 수용한 부분에서 기인 하는 경우가 많기 때문에 전환좌절상황에서는 이전 선택에 대한 후회를 포함하는 것이 설득 력 있을 것이다.

\subsubsection{2 현재 제공자에 대한 원망}

반작용이론에 의하면 사람들은 기본적으로 그 들의 행동적 자유를 유지하고 싶어하며, 만약 행동의 자유가 침해된다면, 그 자유를 지키기 위해 위협에 대해 반응하는데(Brehm 1966), 이 는 자유를 위협한 원천에 대한 분노의 형태로 나타날 수 있다(Dillard and Shen 2005). 분노 는 어떤 외부적 압력으로서, 다른 사람이 나의 계획이나 목표의 추구를 간섭하거나 방해한다 고 지각할 때, 다른 사람이 배신을 하거나 적절 하게 배려하지 않는다고 지각할 때 유발될 수
있는 감정이다. 전환좌절 상황 역시 전환 장벽 에 의해 다른 대안적 제공자로 바꾸는 것을 방 해 받는 상황이기 때문에 어떤 면에서는 분노 의 발생도 자연스러울 수 있지만, 분노는 외부 로 부터의 방해나 비판이 옳지 않다는 생각에 전제 하며(Reeve 2005), 개인의 목표 추구를 방 해하거나 욕구를 좌절시키는 원천에 대해 공격 행동까지 유발할 수 있는 강한 감정이라는 점 에서는(Berkowitz 1990: Lemerise and Dodge 1993: Reeve 2005) 적절하지 않을 수 있다. 왜 냐하면 전환장벽이 현재 제공자와 계약 시 내 가 자율적으로 수긍하고 선택한 부분에서 기인 하는 경우가 많다는 점에서, 전환장벽이 옳지 않다고 생각하기에는 무리가 있기 때문이다. 그 래서 본 연구에서는 현재 제공자에 대한 분노 보다는 그것보다는 약한 감정인 원망을 부정적 심리반응에 포함하였다. 원망은 못마땅하게 여 기어 탓하거나 불평을 품고 미워함이라는 사전 적 의미를 가지며, 분개하여 몹시 성을 내는 것 인 분노에 비해 원망은 비교적 소극적 감정과 표현을 전제한다. 전환상황에서 직면하는 장벽 과 이로 인한 전환의 실패는 나의 선택 때문이 라고 귀인할 가능성이 있으므로 분노보다는 현 재 제공자에 대한 원망이 전환 좌절상황을 반 영하는 부정적 심리반응으로 적절할 것이다.

\subsubsection{3 좌절된 제공자에 대한 열망}

$\mathrm{Brehm}$ (1966)은 사람들이 행동의 자유를 유 지하려고 하며, 만약 그들의 대안이나 소유물이 빼앗긴다면, 제약당한 대안이나 소유물이 비교 적 더 매력적인 것으로 재평가할 것이라고 하 였다. 즉 새로운 제공자로 전환하고 싶거나 전 환 하려고 했다가 장벽으로 인해 그 새로운 제 
공자로의 전환이 차단된 경우, 그 제공자를 더 강하게 원하게 될 수 있다는 것이다. 이 때문에 본 연구에서는 좌절된 제공자에 대한 강한 욕 구를 포함하고자 열렬하게 바람이라는 사전적 정의를 가진 '열망'을 좌절된 제공자에 대한 반 응으로 포함하였다.

즉 심리적 반작용이론에서는 어떤 대안이 이 용가능하지 않을 때 더 원하게 된다고 하였는데 (Clee and Wicklund 1980; Mazis et al. 1973), 마찬가지로 전환장벽에 의해 새로운 제공자로 전환할 수 없을 때 그 좌절된 대안을 더 원하 게 될 가능성이 있고, '열망'은 단순한 호의적 감정 정도의 차원이 아니라 무언가 제약될 때 감정적으로 더 강하게 원하게 된다는 반작용이 론의 작용을 반영하는 구성개념이다.

\section{III. 연구가설의 설정}

본 연구에서는 전환장벽으로 인해 전환을 못 하게 된 상황에 관심을 가지고 연구를 진행하 고 있다. 특히 여기에서 전환 좌절이라는 용어 를 사용한 것은 '좌절'이라는 용어가 가지는 사 전적 의미인 '외부로부터의 방해로 인해 기운 꺾임'을 강조하기 위해서이다. 즉 전환장벽의 존 재로 인해 소비자들이 다른 대안으로 바꾸는 것이 쉽지 않을 것으로 인지하고 전환 의지가 꺽이는 경우를 설명하기 위해 전환 좌절이라는 용어를 사용하였고, 이 상황에서의 소비자들의 어떤 부정적 반응들과 그 영향 요인을 살펴보 고자 한다.

사람들은 어떤 선택의 자유를 가진다고 믿는
경향이 있기 때문에, 이러한 믿음이 외부 힘에 의 해 위협받는다고 지각하면 그 영향력에 저항하려 는 경향이 있다는 것이다(Brehm 1966). Brehm (1966)은 사람들이 행동적 자유를 유지할 필요 를 가지며, 만약 그들의 행동적 자유가 침해된 다면 그 자유를 지키기 위해 위협에 대해 반응 한다는 것이다.

기업으로 인한 전환장벽에 직면한 상황에서도 이 부분은 마찬가지일 수 있다. 즉 장벽으로 인 해 어떤 대안을 가질 가능성은 줄어들지만, 내 면적으로는 그것을 더 갈망하게 될 수도 있을 것이다. 특히 반작용이론에 의하면 그러한 자유 를 제약 받을 경우 화를 내기도 하는데(Dillard and Shen 2005), 마찬가지로 전환 장벽에 의해 소비자의 전환의 자유가 제약될 때도 부정적 반응이 발생할 수 있을 것이다. 심지어 이러한 전환장벽이 고객이 계약 당시 고객이 수긍했던 것의 결과라고 할지라도, 고객입장에서는 본인 의 자유가 제약되는 상황을 기업에 전가함으로 써 어떤 심리적으로 부정적인 반응을 보일 수 있을 것이다. 뿐만 아니라 Clee와 Wichlund(1980) 에 따르면, 사람들이 특정행동을 하는 데 있어 자유가 위협받는다고 느낄 때 위협을 받은 행 동이 더 매력적으로 지각되기도 하기 때문에, 전 환이 어려울 때 더 전환하고 싶어질 수도 있다. 따라서 본 연구에서는 이러한 부분에 초점을 맞춰, 좌절 상황의 어떤 특성들이 앞에 이론적 배경에서 제시한 세 가지 부정적 심리반응에 영향을 주는 가를 연구모형에 포함하였다. 또한 부정적 심리반응의 발생은 현재까지 해당 서비 스 제공자로부터 받은 대우에 따라 조절될 수 있을 것으로 보고, 이와 관련하여 '공정성' 변수 를 조절변수로 추가하였다. 
3.1 전환 좌절상황의 특성과 부정적 심리반응의 관계

본 연구는 앞에 제시한 세 가지 부정적 심리 반응, 즉 이전선택에 대한 후회, 현재 제공자에 대한 원망, 좌절된 제공자에 대한 열망을 포함 하며 이에 어떤 전화좌절 상황의 특성이 영향이 주는 가를 볼 것이다. Brehm과 $\mathrm{Brehm}$ (1981)은 (1)위협받거나 상실된 자유의 중요성과 (2)자 유에 대한 위협의 강도가 클수록 심리적 반작 용이 강해진다고 하였다. 본 연구에서는 이 두 가지를 전환 좌절상황에 적용한 변수인 (1)전 환하지 못하게 된 대안의 매력성과 (2)전환을 막은 장벽의 심각성을 부정적 심리반응에 영향 을 주는 전환 좌절상황의 특성으로 제안하였다.

3.1.1 전환 좌절된 대안의 매력성이 부정적 심리반응에 미치는 영향

대안의 매력도는 현재 기업과의 관계에 귀속 하려는 동기를 낮추는 요인으로 연구되었는데 (Anderson and Narus 1990), 기존 연구에서 다뤄진 대안의 매력도는 전반적으로 시장에 매 력적인 이용 가능한 대안들이 존재하는 가를 의미하는데 반해 좌절된 대안의 매력도는 전환 하고 싶었던 어떤 특정 제공자에 끌렸던 정도 를 의미한다. 본 연구에서는 이러한 전환 좌절 된 대안의 매력도가 세 가지 부정적 심리반응 에 영향을 줄 것으로 보았다.

먼저 전환하지 못하게 된 대안의 매력도는 이 전의 선택에 대한 후회를 유발할 것으로 본다. 후희는 다른 선택을 했더라면 더 좋은 결과가 발생했을 것이라는 생각이 유발하는 부정적 감
정으로(Landman 1993: Zoelenberg, van Dijk, Manstead, and van der Pligt 2000), 이러한 후 회는 선택하지 않은 대안의 모든 긍정적 속성 들을 포기하는 것에 의한 저항 상태에서 유발 될 수 있다(Mowen 1992). 즉 기업의 전환장벽 으로 인해 포기해야 하는 대안이 매력적이라면 그 대안의 긍정적인 결과를 포기하는 것에 대 한 저항상태도 커지고 자연스럽게 후회도 더 발생할 것으로 예상 할 수 있다.

$\mathrm{Brehm}$ 과 Brehm(1981)은 위협받거나 상실된 자유가 얼마나 중요하고 가치 있는 가에 따라 원천에 대한 분노 등 소비자들의 부정적 반응 은 달라질 수 있다고 하였다. 전환 상황에서 대 안의 매력성은 전환했을 때 소비자가 받을 수 있을 것이라고 예상하는 어떤 혜택과 연결된다. 즉 좌절된 대안이 매력적이라면 상실된 전환의 자유의 가치가 더 중요하게 지각되고, 반발이 더 발생하여, 전환을 제약한 원천인 현재 제공 자를 더 탓하게 될 것이다. 따라서 좌절된 대안 의 매력성은 현재 제공자에 대한 원망에 긍정 적 영향을 줄 것으로 예상한다.

그리고 반작용이론에서 검증된 바처럼(Brehm 1972: Clee and Wicklund 1980: Henion and Batsell 1976), 어떤 위협이나 어려움으로 인해 이용가능하지 않게 된 대안이 더 좋게 보일 수 있듯이, 전환할 수 없게 된 대안적 제공자를 더 가지고 싶어질 수도 있다. 특히 그 대안이 매력 적였다는 것은 그 대안으로 더 전환하고 싶었 음을 알 수 있고, 반발도 커져서 그 좌절된 제 공자를 더 원하게 될 것이다. 따라서 전환 좌절 된 대안의 매력성은 그 대안에 대한 열망을 증 가시킬 것으로 예상하고 다음과 같이 가설을 설정하였다. 
가설 1-1: 전환 좌절된 대안의 매력성이 높 을수록 이전에 했던 선택에 대한 후회가 커질 것이다.

가설 1-2: 전환 좌절된 대안의 매력성이 높 을수록 현재 제공자에 대한 원망 이 커질 것이다.

가설 1-3: 전환 좌절된 대안의 매력성이 높 을수록 좌절된 제공자에 대한 열 망이 커질 것이다.

\section{1 .2 전환을 좌절시킨 장벽의 심각성이 부정적 심리 반응에 미치는 영향}

심리적 반작용이론에 의하면, 반작용의 발생 은 자유에 대한 위협의 강도에 따라 달라질 수 있다(Brehm and Brehm 1981), 즉 어떤 자유가 위협받는다고 강하게 지각할수록 심리적 반발 이 커질 수 있으며, 이러한 반발은 부정적 감정 상태로 나타나는 것처럼(Dillard and Shen 2005), 전환의 자유를 크게 제약 당했다고 생각하면 부정적 반응들이 커질 것으로 예상할 수 있다.

본 연구에서는 이러한 전환의 자유를 제약한 정도를 소비자들이 지각하는 전환장벽의 심각 성으로 구성 개념화하였다. '심각성'이라는 용어 는 상태나 정도가 매우 깊고 중대하다는 의미 를 가진다. 즉 전환을 방해한 전환 장벽의 심각 성은 전환 장벽이 어느 정도 강하고 중요하게 소비자의 전환을 막았는가와 관련될 수 있는데, 이러한 전환장벽의 심각성은 이전 선택에 대한 후회, 현재 기업에 대한 원망, 좌절된 대안에 대한 열망과 연결될 수 있다.

먼저 후회는 다른 선택을 했더라면 더 좋았을 것이라는 생각에 의해 발생하므로(Landman 1993),
후회는 선택을 되돌릴 수 없다는 사실을 전제 한다. 만약 전환에 대한 자유의 강하게 제약받 았다면 다른 대안으로 바꿀 수 없음을 강하게 지각했을 것이고, 되돌릴 수 없는 이전의 결정 에 대해 후회를 강하게 경험할 것으로 예상할 수 있다. 그래서 본 연구에서는 전환을 못하게 한 장벽의 심각성이 이전 선택에 대한 후회에 긍정적 영향을 줄 것으로 가정하였다.

또한 차재호와 구자숙(1999)은 관계에서 갈등 의 원인이 되는 감정 차원들이 각각 어떤 상황 에서 유발될 수 있는지를 연구하였는데, '내 일 을 방해하는 행동'의 상황이 사람들을 원망스럽 게 느끼게 할 수 있다고 하였다. 이런 점에서 전환의 어려움이 강했을수록 다른 제공자로 바 꾸는 것을 크게 방해받은 상황이라 할 수 있으 며, 이로 인해 현재 제공자를 더 원망하게 할 것으로 예상할 수 있다.

뿐만 아니라 소비자들은 본인들의 의사결정이 장벽에 의해 방해(부분적 혹은 전체적으로) 받 을 때 그 대안을 획득하고자 점차 동기부여 될 수 있으며(Clee and Wicklund 1980), 자유의 제 약 정도가 심해질 때 이런 영향은 더 강해질 수 있다(Brehm and Brehm 1981). 즉 위협의 정 도가 클수록 위협받은 자유에 대한 큰 갈망을 일으킬 수도 있다고 한 것처럼(Brehm 1966), 전 환의 자유를 심각하게 제약 당했다고 지각할수 록 전환하지 못하는 대안을 더 원하게 될 것으 로 가정하고 다음과 같이 가설을 설정하였다.

가설 2-1: 전환을 좌절시킨 장벽의 심각성이 클수록 이전에 했던 선택에 대한 후회가 커질 것이다.

가설 2-2: 전환을 좌절시킨 장벽의 심각성이 
클수록 현재 제공자에 대한 원망 이 커질 것이다.

가설 2-3: 전환을 좌절시킨 장벽의 심각성이 클수록 전환 좌절된 대안에 대한 열망이 커질 것이다.

\section{2 지금까지 해당 기업에서 받은 대우의 지각된 공정성의 조절}

소비자들은 전환장벽의 방해로 인해 전환이 좌절되는 모든 상황에서 부정적으로 반응할 것 인가? 본 연구에서는 고객이 지금까지 해당기 업으로부터 받은 대우의 공정성에 따라, 전환좌 절상황의 특성이 세 가지 부정적 심리 반응에 주는 영향이 달라질 것으로 예상한다. 즉, 지금 까지 내가 이 기업에 고객으로 있으면서 얼마 나 그 기업으로 부터 합당한 대우를 받아 왔는 가에 따라, 전환이 좌절될 때 발생하는 부정적 반응이 더 증가하거나 감소할 것으로 예상한다. 공정성은 '투자 대 산출'의 비율 차이에 의하는 것으로(Adams 1965), 조직 행동분야(Adams 1965: Lind and Tyler 1988: Masterson et al. 2000 )에서나 마케팅 분야 연구(박미영 외 2010: 윤만희 2003: Blodgett et al. 1997; Oliver and DeSarbo 1988)에서 조직구성원이나 고객의 행 동에 영향을 주는 주요 변수로 다뤄졌다. 본 연 구에서의 공정성은 단속적 거래에서 투입한 비 용에 대비해 어떤 혜택들을 얻었는가에 초점을 맞추는 것이 아니라, 지금까지 거래를 지속해 오면서 축적된 전반적인 대우의 공정성에 초점 을 맞춘다. 이런 점에서 어떤 조직에 소속된 구 성원이 지각하는 공정성에 관한 연구와 좀 더 가까운 것으로 보고 그에 관한 연구를 참조하
였고 다음의 세 가지 공정성을 포함한다.

먼저 결과공정성은 개인이 투입한 노력에 대 해 물질적이고 명시적인 보상(Lind and Tyler 1998)을 의미하는 것으로 최종적으로 지급되는 어떤 결과물의 분배와 관련(Rutte and Messick 1995)되는 것이다. 이는 고객이 현재 제공자를 이용하는 동안 소비자가 직간접적 기여한 바에 비해 받은 혜택이나 보상 등이 합당한지와 관 련될 수 있다. 즉 거래하는 동안 내가 이 제공 자에 기여했다고 생각하는 부분들(예를 들어 실질적 구매 기여, 혹은 주위사람에게 추천을 통한 간접적 기여)에 비해 제공받은 결과적 제 공물이 공정한지를 포함할 것이다.

절차공정성은 보상을 전달하는 과정에 있어 전달 절차나 시스템 상의 유연성, 반응성, 신속 성. 효율성, 접근성 등에 해당하는데(Clemmer 1993), 이는 현재 제공자를 이용하는 동안 이 제공자가 고객이 원하는 바에 대해서 신속하고 유연하게 그리고 효율적으로 처리해 주었는가 와 관련된다.

상호작용공정성은 인간의 상호관계적 측면에 서 어떻게 대우 받는가에 대한 지각으로서(Bies and Moag 1986). 종업원의 고객에 대한 진실성. 친절, 우애, 민감성, 설명, 관심, 예의 등이 포함될 수 있다(Bies and Moag 1986: Clemmer 1993). 즉 이 제공자와 거래하는 동안 어느 정도 인간 적으로 좋은 대우를 받았는가와 관련된다.

이러한 공정성은 조직원들의 직무만족과 조직 결속에 중요한 역할을 하는 것으로 밝혀졌으며 (Lind and Tyler 1988), 구성원들이 자신이 조 직 내에서 공정한 대우를 받았다고 지각할 경우 조직에 대해 긍정적인 태도를 취하며, 이직 의 도도 감소하는 것으로 알려져 있다(Folger and 
Konovsky 1989; Masterson et al. 2000). 뿐만 아니라 소비자와 관련해서도 소비자 만족(Oliver and DeSarbo 1988), 재구매의도 및 구전 의사 결정(Blodgett, Hill and Tax 1997), 서비스 실 패 상황의 처리(Tax, Brown, Chandrashekaran 1998)에 있어서도 중요한 역할을 하는 것으로 나타났다. 이렇듯 공정성은 소속된 어떤 조직과 의 관계나 거래하는 기업과의 관계에서 어떤 긍정적 분위기 조성에 중요한 부분임을 알 수 있으며, 이는 전환좌절 상황에서도 마찬가지일 것이다.

즉 조직구성원들이 조직으로 부터 어떤 대우 를 받았는가에 따라 어떤 시점의 불만족과 이 직의도가 달라지듯이(Lind and Tyler 1988), 서 비스 제공자가 설정한 전환장벽으로 인해 전환 할 수 없는 상황에서, 전환할 수 없는 대안이 매력적이거나 전환장벽이 강하게 제약했다고 하
더라도, 해당 제공자가 지금까지 나를 공정하게 잘 대우해주었다고 생각하면 어떤 부정적 반응 이 덜할 것으로 예상할 수 있다. 따라서 본 연 구에서는 다음과 같이 가설을 설정하였다.

가설 3-1: 전환 좌절된 대안의 매력성이 이 전 선택에 대한 후회에 주는 긍정 적 영향은 지각된 공정성(결과/절 차/상호작용)이 높은 집단에 비해 낮은 집단에서 더 클 것이다.

가설 3-2: 전환 좌절된 대안의 매력성이 현 재 제공자에 대한 원망에 주는 긍 정적 영향은 지각된 공정성(결과) 절차/상호작용)이 높은 집단에 비 해 낮은 집단에서 더 클 것이다.

가설 3-3: 전환 좌절된 대안의 매력성이 좌 절된 제공자에 대한 열망에 주는

\section{〈그림 1〉 전환좌절 상황의 특성이 소비자의 부정적 심리반응에 주는 영향}

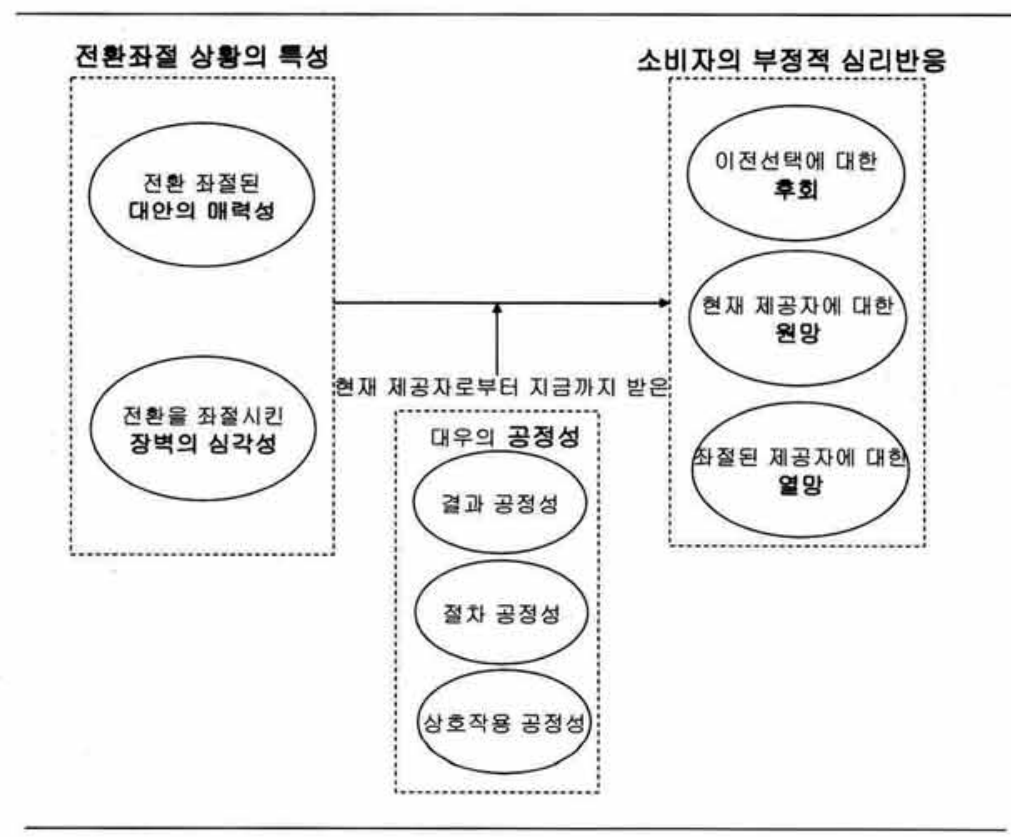


긍정적 영향은 지각된 공정성(결 과/절차/상호작용)이 높은 집단에 비해 낮은 집단에서 더 클 것이다.

가설 4-1: 전환을 좌절시킨 장벽의 심각성이 이전 선택에 대한 후회에 주는 긍 정적 영향은 지각된 공정성(결과) 절차/상호작용)이 높은 집단에 비 해 낮은 집단에서 더 클 것이다.

가설 4-2: 전환을 좌절시킨 장벽의 심각성이 현재 제공자에 대한 원망에 주는 긍정적 영향은 지각된 공정성(결 과/절차/상호작용)이 높은 집단에 비해 낮은 집단에서 더 클 것이다. 가설 4-3: 전환을 좌절시킨 장벽의 심각성이 좌절된 제공자에 대한 열망에 주 는 긍정적 영향은 지각된 공정성 (결과/절차/상호작용)이 높은 집 단에 비해 낮은 집단에서 더 클 것이다.

\section{IV. 연구방법}

\section{1 측정을 위한 항목 추출}

본 연구에서는 기존 연구와 유사한 구성개념 을 포함하고 있지만 그 의미적 부분에서는 약 간씩 차이가 있기 때문에, 이전 연구에서 쓰였 던 측정항목을 참조하되 연구 방향과 내용에 맞게 수정하여 사용하였다.

먼전 전환 좌절된 대안의 매력성은 특정 대안
의 매력성을 의미하기 때문에 기존 연구에서 사용된 대안의 매력성에 관한 연구(Anderson and Narus 1990)와 매력성(Ohanian 1990)에 관한 연구를 함께 수정하여 문항에 포함하였다. 그리고 전환을 좌절시킨 장벽의 심각성은 심리 적 반작용 이론의 개념적 부분(Brehm 1966)과 서비스 실패의 심각성에 관한 측정항목(Hess 2008)을 참조하여, 전환을 좌절시킨 장벽의 위 협정도나 제약정도에 초점을 맞춰 측정도구를 수정하여 측정에 사용하였다.

부정적 심리반응 중 이전 선택에 대한 후회는 Glovich와 Medvec(1995)의 측정항목을 참조하 여 3 개 문항으로 사용하였고, 원망은 차재호와 구자숙(1999)의 연구에서 제시된 내용을 참조 하여 3 개 항목으로 측정하였다. 또한 좌절된 제 공자에 대한 열망은 열망과 관련된 다른 분야 의 연구들(Alcohol Urge Questionaire(Bohn et al. 1995)을 수정하여 사용하였다. 그리고 지각 된 공정성은 결과공정성(Lind and Tyler 1998), 절차공정성(Clemmer 1993), 상호작용공정성(Bies and Moag 1986)에 관한 연구를 참조하고 수정 하여 사용하였다.

이 연구에서 제시한 설문 항목들은 예비검증 절차를 거쳤으며, 예비검증 결과에 기초해 각 구성개념 별로 세 개 항목씩을 측정에 사용하 였다. 측정에는 리커트형 7점 척도(전혀 그렇지 않다:1점 - 매우 그렇다: 7점)를 이용하였다.

\section{2 조사대상과 자료수집}

본 연구에서는 서비스 분야를 포괄해서 기업 에서 설정한 전환장벽에 의해 전환이 어렵게 된 상황에서 발생하는 부정적 심리반응과 그에 
영향을 주는 전환 좌절 상황의 특성, 그리고 지 각된 공정성의 조절 영향을 설명하는 모형을 검증하고자 한다. 본 연구는 '전환좌절상황'이라 는 특수한 상황에 대한 정확한 이해 하에 응답 해야 하고 주관식 문항도 포함하고 있기 때문 에, 설문에 비교적 많은 시간을 할애할 수 있는 20 30대 대학생과 대학원생을 중심으로 2011 년 3 월부터 5 월까지 몇 차례에 걸쳐 편의표본 추출하였다. 자료 수집과정에서는 먼저 설문 진 행자들이 연구의 목적과 설문응답방법을 설명 한 후, 응답자들이 설문에 포함된 주관식과 객 관식 항목에 응답하는 방식으로 하였다.

전환좌절상황에서 좌절, 즉 '외부로부터의 방 해로 인해 기운 꺽임'의 의미와 일관되게, 소비 자들이 전환장벽으로 인해 전환을 단념한 상황 이기 때문에 이와 관련한 데이터만을 선별할 필요가 있었다. 응답자들에게 여러 가지 상황적 사례를 제시하며 충분히 설명하였으며, 이를 위 해 연구에 대해 정확히 이해하고 있는 숙련된 진행자들이 자료수집과정에 참여하였다. 또한 회상률을 높이고 정확한 응답이 진행되었는지 를 확인하기 위해 다음의 주관식 문항을 포함 하고, 객관식 설문 항목의 응답 전에 이 부분에 대해 먼저 서술하도록 요청하였다.

먼저 설문지의 처음 시작 부분에 응답에 이용
할 최근 서비스에서의 전환하고자 하였으나 어 떤 외부적 어려움 때문에 단념했던 경험(한 달 이내로 제한/ 서비스의 종류, 내용, 가입 시기, 이용 장소, 제공자 등을 포함)을 구체적으로 적 게 하고, 바로 다음 부분에 이 서비스를 다른 서비스로 전환하고자 할 때의 상황(부딪힌 전 환장벽의 종류와 내용, 전환하고자 한 시기 등) 에 대해 상세히 적도록 요청하였다. 이는 응답 자의 머릿속에서 어떤 구체적인 상황을 자세히 회상하게 함으로써 설문에 좀 더 정확하게 응 답하도록 하기 위해서이며, 또한 본 연구 의도 나 내용에 적합한 데이터를 신중하게 선별하기 위해서이다.

총 270 부의 설문지 중에서 249 부가 회수되 었는데, 이들 중에서 불성실하거나 본 연구의 범위와 맞지 않는 설문을 제외시키기 위해 앞 에 제시했던 주관식 응답을 세밀하게 검토하는 과정을 거쳤다. 분류 과정에서는 연구에 대해 잘 이해하고 있는 석사과정의 연구자 2 명이 본 연구의 연구자들과 함께 참여하였고, 이러한 과 정을 거친 후 분석에 사용된 설문은 총 194 부 이다. 분석에 사용된 194 부에는 남자. $58.25 \%)$ 가 여자 $(41.75 \%)$ 보다 많았고, 25 세에서 30 세까 지 $(41.75 \%)$ 가 표본의 대다수를 차지하였다. 표 본에 포함된 서비스에는 통신서비스( $31.44 \%)$ 가

〈표 1〉 표본의 일반적 특성

\begin{tabular}{|c|c|c|c|c|c|c|c|}
\hline \multicolumn{2}{|c|}{ 구분 } & \multirow{2}{*}{$\begin{array}{c}\text { 빈도(명) } \\
113\end{array}$} & \multirow{2}{*}{$\begin{array}{c}\text { 비율(\%) } \\
58.25\end{array}$} & \multicolumn{2}{|c|}{ 구분 } & \multirow{2}{*}{$\begin{array}{c}\text { 빈도(명) } \\
61\end{array}$} & \multirow{2}{*}{$\begin{array}{c}\text { 비율(\%) } \\
31.44\end{array}$} \\
\hline 서벼 & 남 & & & \multirow{5}{*}{$\begin{array}{l}\text { 표본에 } \\
\text { 포함된 } \\
\text { 서비스 }\end{array}$} & 통신사 서비스 & & \\
\hline 성멸 & 여 & 81 & 41.75 & & 보험 등 & 47 & 24.23 \\
\hline \multirow{3}{*}{ 연령 } & 19세 24세 & 68 & 35.05 & & & & \\
\hline & 25세 30세 & 81 & 41.75 & & $\begin{array}{c}\text { 인터넷 중심의 } \\
\text { 서비스 }\end{array}$ & 57 & 29.38 \\
\hline & 31세 이상 & 45 & 23.20 & & 기타 & 29 & 14.95 \\
\hline
\end{tabular}


가장 많은 비율을 차지하고 있고, 다음으로 온 라인 강의 등을 포함하는 인터넷 중심의 서비 스(29.38\%), 보험 등 금융서비스(24.23\%), 기 타(14.95\%)를 포함하였다.

\section{V. 분석과 결과}

\section{1 기초분석}

〈표 2〉는 변수의 평균과 표준편차, 상관계수 를 보여주고 있으며, 각 변수의 상관계수가 가 설에서 제시한 방향과 일치함을 알 수 있다. 특 히 독립변수인 전화 좌절된 대안의 매력성 변 수 $(\mathrm{M}=4.66, \mathrm{SD}=1.48)$, 전환을 좌절시킨 장벽 의 심각성 변수 $(\mathrm{M}=3.66, \mathrm{SD}=1.78)$ 와 종속변 수인 후희 $(\mathrm{M}=3.45, \mathrm{SD}=1.69)$, 원망( $\mathrm{M}=3.15$, $\mathrm{SD}=1.75)$, 열망 $(\mathrm{M}=4.19, \mathrm{SD}=1.69)$ 의 상관계 수의 값은 .214 .599로 긍정적 방향에서 높게 나타났다. 이는 좌절 상황의 특성이 부정적 심 리에 미치는 긍정적 영향을 의미하는 결과로
해석할 수 있다.

\section{2 가설 1 과 가설 2 의 검증: (전환 좌절된) 대안의 매력성과 (전환을 좌절시킨) 전환 장벽의 심각성의 주 효과 분석}

본 연구는 전환 좌절 상황의 특성[-전환 좌절 된 대안의 매력성과 전환을 좌절시킨 전환 장 벽의 심각성-]이 부정적 심리 반응[-이전 선택 에 대한 후회, 현재 제공자에 대한 원망, 좌절 된 제공자에 대한 열망-]에 미치는 주 효과 (main effect)와 이들 변수 간 관계에서 지각된 공정성[-결과공정성, 절차공정성, 상호작용공정 성-]의 조절효과를 확인하는 것을 주요 연구가 설로 설정하였다. 이러한 가설검증을 위해 시행된 계층적 회귀분석(hierarchical regression analysis) 의 결과는〈표 3〉과〈표 4〉에 요약되어 있다. 본 연구에서는 상호작용 항목을 회귀방정식에 포함된 변수들의 곱으로 하고 있기 때문에, 이 들 상호작용 항목들이 독립변수들과 다중공선 성을 야기할 수 있다(Aiken and West 1991; 박상언 2009). 따라서 본 연구에서는 이 문제를

〈표 2〉연구변수들 간의 상관관계( $N=194)$

\begin{tabular}{|l|c|c|c|c|c|c|c|c|c|c|}
\hline & 평균 & $\begin{array}{c}\text { 표준 } \\
\text { 편차 }\end{array}$ & 1 & 2 & 3 & 4 & 5 & 6 & 7 & 8 \\
\hline 1. 대안의 매력성 & 4.66 & 1.48 & 1 & & & & & & & \\
\hline 2. 장벽의 심각성 & 3.66 & 1.76 & $.177^{*}$ & 1 & & & & & & \\
\hline 3. (이전선택)후회 & 3.45 & 1.69 & $.353^{* *}$ & $.295^{* *}$ & 1 & & & & & \\
\hline 4. (현재제공자)원망 & 3.15 & 1.75 & $.299^{* *}$ & $.214^{* *}$ & $.745^{* *}$ & 1 & & & & \\
\hline 5. (좌절된제공자)열망 & 4.19 & 1.69 & $.599^{* *}$ & $.224^{* *}$ & $.602^{* *}$ & $.531^{* *}$ & 1 & & & \\
\hline 6. 결과 공정성 & 3.64 & 1.26 & $-.250^{* *}$ & $-.144^{*}$ & $-.216^{* *}$ & -.085 & $-.149^{*}$ & 1 & & \\
\hline 7. 절차 공정성 & 3.69 & 1.37 & $-.300^{* *}$ & -.114 & $-.333^{* *}$ & $-.178^{*}$ & $-.272^{* *}$ & $.677^{* *}$ & 1 & \\
\hline 8. 상호작용 공정성 & 4.07 & 1.33 & -.129 & -.038 & $-.338^{* *}$ & $-.266^{* *}$ & $-.251^{* *}$ & $.357^{* *}$ & $.432^{* *}$ & 1 \\
\hline
\end{tabular}


해결하기 위해 모든 변수들의 원자료를 중심화 한 후에 상호작용항을 포함하였다.

이전 선택에 대한 후회, 현재 제공자에 대한 원망, 좌절된 제공자에 대한 열망 등 3 개의 종 속변수에 대해, 첫 번째 단계에서는 전환 좌절 된 대안의 매력성〈표 3 과 전환장벽의 심각성 〈표 4〉 등 독립변수가 투입되었고(모형 I), 두 번째와 세 번째 단계에서는 공정성의 조절효과 를 확인하기 위해 결과공정성, 절차공정성, 상 호작용공정성(모형 II) 과 대안의 매력성과 공정 성의 상호작용 항목들이 투입되었다(모형 III)

〈표 3〉과〈표 4〉의 분석결과에 의하면, 전환 좌절된 대안의 매력성과 전환을 좌절시킨 장벽 의 심각성이 후회, 원망, 열망에 미치는 영향이 모두 가정한 바대로 유의한 긍정적 영향이 나 타났다. 즉 전환하지 못한 대안이 매력적일수록 이전에 했던 선택에 대한 후회나 현재 제공자 에 대한 원망, 좌절된 대안에 대한 열망이 강해 짐을 알 수 있어 가설 1 은 지지되었다. 또한 전 환을 좌절시킨 장벽이 심각하다고 지각할수록 후회, 원망, 열망이 강해지는 것으로 나타나 가 설 2도 지지되었다.

\section{3 가설 3 과 가설 4 의 검증: 공정성의 조절 효과 분석}

전환좌절 상황의 특성이 일련의 종속변수들에 미치는 영향관계에 있어서, 공정성이 수행하는 조절효과를 확인하기 위해 가설 3 과 가설 4 의 검증결과는 〈표 3 ᄀ과 〈표 4 〉의 모형 III에서 확 인할 수 있다. 먼저, 전환 좌절된 대안의 매력 성의 영향의 경우는 후회에 주는 영향에서는 결과공정성만이 유의적인 상호작용 효과를 보
여주고 있으며, 상호작용 항목이 추가된 모형 III 은 그 이전 모형에 비해 설명력 $\left(R^{2}\right)$ 이 $23.0 \%$ 에서 $30.4 \%$ 로 증가한 것으로 나타났다. 그리고 현재 제공자에 대한 원망과 좌절된 제공자에 대한 열망에 대한 영향에서는 상호작용공정성 의 유의적인 상호작용 효과가 관찰되었고, 모형 III의 설명력 $\left(R^{2}\right)$ 이 이전 모형에 비해 증가하였 다 $(11.7 \% \rightarrow 19.3 \%, 24.6 \% \rightarrow 41.4 \%)$. 이러한 분 석 결과에서 볼 때 공정성의 조절효과는 결과 공정성, 절차 공정성, 상호작용 공정성 모두의 상호작용 효과가 유의하지는 않지만, 각각 한 개의 공정성의 상호작용 효과가 나타나고 있어, 가설 3 은 일부 지지되었다.

또한 전환을 어렵게 한 전환 장벽의 심각성이 부정적 심리반응에 주는 영향에서도 공정성의 조절효과는 일부 유의한 것으로 나타났다. 즉 전환 장벽의 심각성이 이전 선택에 대한 후희 에 주는 영향과 현재 제공자에 대한 원망, 좌절 된 제공자에 대한 열망에 주는 영향 모두에서 상호작용 공정성만이 유의적인 상호작용 효과 를 나타내고 있어, 가설 4 도 일부 지지되었다.

이러한 상호작용효과를 그래프로 나타내기 위 하여 결과 공정성과 상호작용 공정성의 평균값 에서 1 단위 이상 높거나 낮은 두 집단을 대상 으로 해서(M+1SD: $\mathrm{M}-1 \mathrm{SD})$, 전환 좌절된 대 안의 매력성 및 전환장벽의 심각성과 부정적 심리반응 간 관계를 단순회귀 분석하여 기울기 를 비교해 보았다(Aiken and West 1991). 〈그 림 2〉는 전환 좌절된 대안의 매력성과 부정적 심리반응의 관계에서 지각된 공정성이 수행하 는 상호작용효과의 양상을 보여주고 있다. 이에 따르면, 상대적으로 결과 공정성을 높게 지각하 는 집단은 대안의 매력성과 후회와의 관계가 
〈표 3〉 계층적 회귀분석 결과: 전환 좌절된 대안의 매력성의 영향

\begin{tabular}{|c|c|c|c|c|c|c|c|c|c|}
\hline & \multicolumn{3}{|c|}{ 이전 선택에 대한 후회 } & \multicolumn{3}{|c|}{ 현재 제공자에 대한 원망 } & \multicolumn{3}{|c|}{ 좌절된 제공자에 대한 열망 } \\
\hline & 모형 I & 모형 II & 모형 II & 모형 I & 모형 II & 모형 III & 모형 I & 모형 II & 모형 III \\
\hline 대안의 매력성(AA) & $.353^{* * *}$ & $.282^{* * *}$ & $.212^{* *}$ & $.174^{*}$ & $.202^{* *}$ & $.158^{*}$ & $.265^{* * *}$ & $.401^{* * *}$ & $.497^{*}$ \\
\hline 결과 공정성(DJ) & & $-.245^{* *}$ & $-.510^{*}$ & & -.087 & -.119 & & -.072 & -.001 \\
\hline 절차 공정성(PJ) & & -.070 & -.067 & & -.071 & -.156 & & -.122 & -.281 \\
\hline 상호작용 공정성 (IJ) & & $-.190^{*}$ & $-.311^{* *}$ & & $-.289^{* * *}$ & $-.500^{* * *}$ & & $-.269^{* * *}$ & $-.457^{*}$ \\
\hline $\mathrm{AA} \times \mathrm{DJ}$ & & & $-.209^{* *}$ & & & -.034 & & & -.220 \\
\hline $\mathrm{AA} \times \mathrm{PJ}$ & & & -.010 & & & -.152 & & & -.412 \\
\hline $\mathrm{AA} \times \mathrm{IJ}$ & & & -.355 & & & $-.158^{*}$ & & & $-.511^{*}$ \\
\hline Overall $\mathrm{F}$ & $27.289^{* * *}$ & $14.126^{* * *}$ & $11.619^{* * *}$ & $6.027^{*}$ & $6.286^{* * *}$ & $6.349^{* * *}$ & $14.516^{* * *}$ & $15.375^{* * *}$ & $18.796^{* * *}$ \\
\hline$R^{2}$ & .124 & .230 & .304 & .030 & .117 & .193 & .070 & .246 & .414 \\
\hline 조정 $R^{2}$ & .120 & .214 & .278 & .025 & .099 & .162 & .065 & .230 & .392 \\
\hline$\Delta R^{2}$ & & .194 & .064 & & .074 & .063 & & .165 & .162 \\
\hline
\end{tabular}

1) 제시된 수치는 표준화된 회퀴계수임

〈표 4〉 계층적 회귀분석 결과: 전환을 좌절시킨 장벽의 심각성의 영향

\begin{tabular}{|c|c|c|c|c|c|c|c|c|c|}
\hline & \multicolumn{3}{|c|}{ 이전 선택에 대한 후회 } & \multicolumn{3}{|c|}{ 현재 제공자에 대한 원망 } & \multicolumn{3}{|c|}{ 좌절된 제공자에 대한 열망 } \\
\hline & 모형 I & 모형 II & 모형 III & 모형 I & 모형 II & 모형 II & 모형 I & 모형 II & 모형II \\
\hline 장벽의 심각성(BS) & $.197^{* *}$ & $.181^{* *}$ & $.196^{* *}$ & $.214^{* *}$ & $.207^{* *}$ & $.205^{* *}$ & $.254^{* * *}$ & .228 & $.202^{* *}$ \\
\hline 결과공정성(DJ) & & .035 & -.095 & & -.119 & -.111 & & -.092 & -.020 \\
\hline 절차공정성(PJ) & & $-.234^{*}$ & $-.213^{*}$ & & -.129 & -.120 & & -.121 & -.156 \\
\hline 상호작용공정성(IJ) & & $-.250^{* *}$ & $-.181^{*}$ & & $-245^{* *}$ & $-.284^{* *}$ & & $-.272^{* * *}$ & $-.228^{*}$ \\
\hline $\mathrm{AA} \times \mathrm{DJ}$ & & & -.006 & & & -.016 & & & -.035 \\
\hline $\mathrm{AA} \times \mathrm{PJ}$ & & & -.049 & & & -.069 & & & -.116 \\
\hline $\mathrm{AA} \times \mathrm{IJ}$ & & & $-.188^{*}$ & & & $-.188^{* *}$ & & & $-.167^{*}$ \\
\hline Overall $\mathrm{F}$ & $7.753^{* *}$ & $11.116^{* * *}$ & $7.421^{* * *}$ & $9.246^{* *}$ & $6.592^{* * *}$ & $5.172^{* * *}$ & $13.231^{* * *}$ & $7.462^{* * *}$ & $5.466^{* * *}$ \\
\hline$R^{2}$ & .039 & .190 & .218 & .046 & .122 & .163 & .064 & .136 & .171 \\
\hline 조정 $R^{2}$ & .034 & .173 & .189 & .041 & .104 & .131 & .060 & .118 & .139 \\
\hline$\Delta R^{2}$ & & .139 & .016 & & .063 & .027 & & .058 & .021 \\
\hline
\end{tabular}

*** $\mathrm{p}<.001,{ }^{* *} \mathrm{p}<.01,{ }^{*} \mathrm{p}<.05$

1) 제시된 수치는 표준화된 회귀계수임 
긍정적 관계를 가지긴 하지만, 그 정도가 유의 적이지 않은 반면 $(\mathrm{b}=.130, \mathrm{t}=.965, \mathrm{n.s})$, 상대적 으로 결과공정성을 낮게 지각하는 집단에서는 후회가 유의적으로 증가함을 확인할 수 있다 $(\mathrm{b}=.431, \mathrm{t}=3.240, \mathrm{p}<.01)$, 즉, 대안의 매력성 이 후회에 주는 긍정적 영향은 결과 공정성을 낮게 지각하는 집단에서 좀 더 크게 나타나고 있는 것이다. 이로써, 결과공정성은 대안의 매
력성이 후회에 미치는 긍정적 영향을 일정하게 완충시키고 있음을 확인할 수 있다. 또한 대안 의 매력성과 현재 제공자에 대한 원망과 좌절 된 제공자에 대한 열망에 주는 영향은 상호작 용 공정성의 지각에 따라 달라지는 것으로 나 타났다. 대안의 매력성이 현재 제공자에 대한 원망에 주는 영향은 상대적으로 상호작용 공정 성을 높게 지각하는 집단 $(\mathrm{b}=.177, \mathrm{t}=2.102, \mathrm{p}<$

〈그림 2〉 부정적 심리반응에 대한 대안의 매력성과 공정성의 상호작용효과
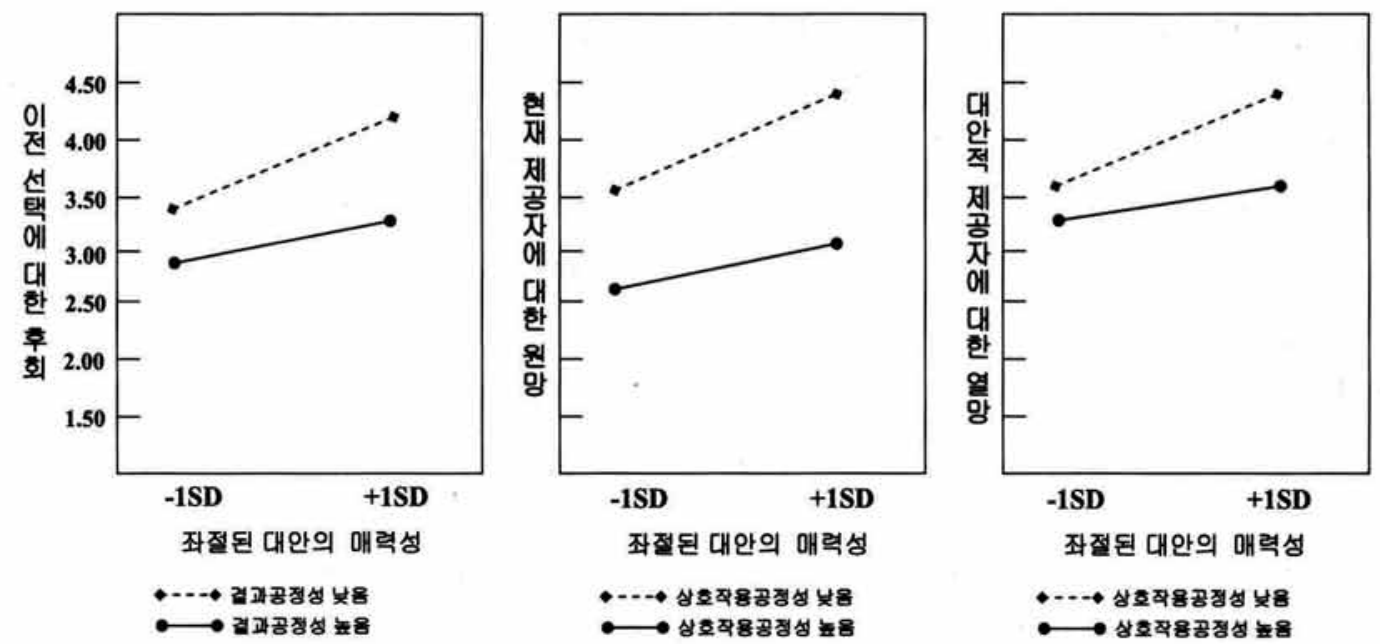

〈그림 3〉 부정적 심리반응에 대한 장벽의 심각성과 공정성의 상호작용효과
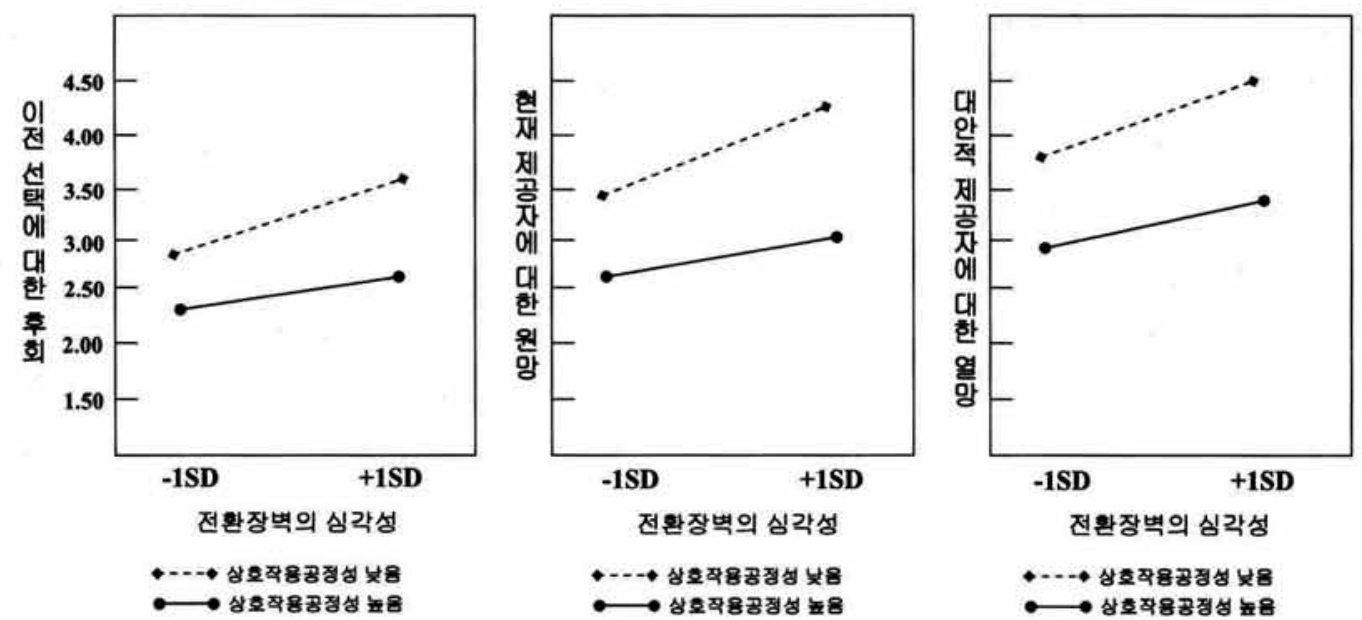
.05)에 비해, 상호작용 공정성을 낮게 지각하는 집단 $(\mathrm{b}=.396, \mathrm{t}=2.672, \mathrm{p}<.01)$ 에서 더 큰 것으 로 나타났다. 마찬가지로 좌절된 제공자에 대한 열망에 대한 영향도 상호작용 공정성을 높게 지각하는 집단 $(b=.155, t=2.102, p<.05)$ 보다 상 호작용 공정성을 낮게 지각하는 집단 $(\mathrm{b}=.449$, $\mathrm{t}=2.509, \mathrm{p}<.05)$ 에서 큰 것으로 나타났다.

전환을 좌절시킨 장벽의 심각성이 부정적 심 리반응에 주는 영향에 있어서도 상호작용 공정 성만이 조절효과를 가지는 것으로 나타났다. 이 전 선택에 대한 후회에 주는 영향에 있어서는 상호작용 공정성이 비교적 높게 지각하는 집단 $(\mathrm{b}=.150, \mathrm{t}=1.559, \mathrm{n} . \mathrm{s})$ 에 비해 비교적 낮게 지 각하는 집단 $(\mathrm{b}=.373, \mathrm{t}=1.995, \mathrm{p}<.05)$ 에서 큰 것으로 나타났으며, 현재 제공자에 대한 원망에 주는 영향도 상호작용 공정성을 비교적 높게 지각하는 집단 $(\mathrm{b}=.125, \mathrm{t}=1.245, \mathrm{n} . \mathrm{s})$ 에 비해 낮게 지각하는 집단 $(\mathrm{b}=.390, \mathrm{t}=4.005, \mathrm{p}<.01)$ 에서 크게 나타났다. 마찬가지로 좌절된 제공자 에 대한 열망에 주는 영향도 상호작용 공정성 을 비교적 높게 지각하는 집단보다 $(\mathrm{b}=.165, \mathrm{t}=$ $1.977, \mathrm{p}<.05)$ 낮게 지각하는 집단 $(\mathrm{b}=.343, \mathrm{t}=$ $2.767, \mathrm{p}<.01)$ 에서 크게 나타났다.

이러한 결과에서 볼 때, 결과 공정성과 상호 작용 공정성의 조절효과만 지지됨으로써 가설 3 과 4 는 일부 지지되었지만, 공정성을 높게 지 각하는 집단에서 전환좌절상황의 특성이 부정 적 심리반응에 미치는 영향이 덜 할 것이라는 가설은 지지하고 있다.

\section{VI. 결론과 토론}

\section{1 연구결과의 요약}

본 연구는 심리적 반작용이론에 근거하여, 전 환좌절 상황에서 발생한 수 있는 부정적 심리 반응과 그에 영향을 주는 전환좌절상황의 특성, 그리고 전환좌절 상황의 부정적 영향을 경감시 킬 수 있는 공정성의 역할을 제시하고 있다. 이 는 전환장벽을 전환 자유의 박탈이라는 측면에 서 접근함으로써 전환장벽의 가능한 부정적 영 향에 대한 구체적인 제안과 검증을 시도하고 있는 것으로, 이에 따른 연구의 결과를 정리하 면 다음과 같다.

첫째, 좌절된 대안의 매력성이 (이전 선택)후 회, (현재 제공자)원망, (좌절된 제공자)열망 에 주는 영향에 있어서는, 예상한대로 전환하지 못 하게 된 새로운 제공자가 매력적일수록 선택에 대한 후회, 현재 제공자에 대한 원망, 가지 못한 그 새로운 대안에 대한 열망이 커지는 것으로 나타났다. 즉 심리적 반작용이론에서 어떤 자유 가 가치 있다면 더 그에 대한 반발이 커지는 것 처럼(Brehm and Brehm 1981), 전환장벽에 있 어서도 그 새로운 제공자로의 전환 자유의 가 치. 즉 전환하고 싶었던 대안이 매력적이라면 내가 했던 선택을 더 후회하고, 현재 거래하고 있는 제공자를 더 원망할 수 있으며, 전환장벽 때문에 가지 못하고 바라만 봐야하는 새로운 제 공자를 더 강하게 원하게 될 수 있다는 것이다.

둘째, 전환을 좌절시킨 전환장벽의 심각성이 (이전 선택)후회. (현재 제공자)원망, (좌절된 제공자)열망에 주는 영향의 가설 검증결과, 전 
환을 좌절시킨 전환장벽이 강하거나 중요했을 수록 후회나 원망과 같은 부정적 반응이 커지 거나, 이용가능하지 않은 대안에 더 끌리게 되 는 것으로 나타나서 예상했던 바를 지지하고 있다. 즉 위협 받을수록 부정적 반응이 더 발생 하거나 가지지 못하는 대안에 대한 욕구가 커 진다는 심리적 반작용이론(Brehm and Brehm 1981; Clee and Wicklund 1980: Dillard and Shen 2005)이 전환장벽과 관련한 소비 상황에 서도 적용됨을 확인할 수 있었다.

셋째, 지각된 공정성의 조절 영항은 검증결과, 하나를 제외하고 대부분의 영향에서 상호작용 공정성의 조절 영향만이 발견되었다. 즉 전환좌 절상황에서 좌절된 대안이 매력적일수록 그리 고 전환을 못하게 막은 장벽이 심각할수록 부 정적 심리반응이 증가하지만, 소비자들이 현재 기업에서 인간적으로 친절하게 대해주었다고 지각한다면 이러한 영향이 덜해진다는 것이다. 이는 모든 공정성이 조절할 것이라는 가설 중 에서 일부만을 지지하는 결과인데, 본 연구에서 포함한 결과변수가 감정적 부분임을 고려할 때 제공자의 친절도를 반영하는 상호작용공정성의 조절영향이 주로 나타난 것으로 생각해 볼 수 있다. 만약 연구모형에서 실질적인 행동과 관련 한 결과변수가 포함되었다면 지각된 공정성의 조절영향이 달라졌을 가능성도 있기 때문에 이 러한 부분은 차후 연구에서 확인이 필요하다.

그리고 좌절된 대안의 매력성이 이전 선택에 대한 후회에 주는 영향에 있어서만은 상호작용 공정성이 아닌 결과공정성이 조절영향을 가지 는 것으로 나타났다. 이는 대안의 매력성이 이 용하지 못하는 새로운 대안의 어떤 혜택에 대 한 기대와 연결됨과 동시에, 후회도 어떤 선택
하지 않음으로써 놓친 어떤 결과적 부분과 관 련될 수 있기 때문에(Landman 1993), 이 두 변수의 관계에서는 결과공정성, 즉 현재까지 받 은 결과적 제공물이 얼마나 합당한지에 따라 그 영향이 달라지는 것으로 나타났을 수 있다.

\section{2 연구의 시사점}

기존에 전환장벽(혹은 전환비용)에 대한 대다 수의 연구들이 장벽으로 인해 전환을 못하게 됨 으로써 기업에 남게 만드는 기업관점의 긍정적 결과에 중점을 두었다면, 이 연구는 원하는 대 안이 있는데 전환장벽으로 인해 바꾸지 못하는 소비자의 속마음에 조금 더 접근하여 연구를 진 행하고 있다는 시사점을 가진다. 즉 전환장벽으 로 인해 전환이 좌절되었을 때 발생할 수 있는 부정적 심리 반응에 초점을 맞춤으로써, 전환장 벽으로 인해 이뤄지는 표면적인 고객 유지가 아 닌 내면적인 가능한 부정적 반응을 보여주고자 하였다. 구체적인 이론적 시사점은 다음과 같다.

첫째, 전환장벽의 부정적 역할의 가능성에 대 해서는 일부 연구에서 언급이 되었지만(John 2001), 구체적으로 어떤 구성개념들이 이러한 상황을 잘 설명하고 있는지를 보여준 연구는 부족하다. 이 연구에서는 전환장벽에 대한 부정적 시각을 제안하되, 구체적으로 전환상황에서의 어떤 특 성들이 부정적 반응과 연결되는지를 제안하고 검증함으로써 전환장벽의 부정적 영향에 비교 적 상세하게 접근하고 있다는 시사점을 가진다.

둘째, 전환장벽에 대해서 좀 더 소비자의 시 각에서 접근하고 있다는 의의가 있다. 연구결 과, 전환하지 못한 소비자들이 현재 제공자와 관계유지를 하고 있다하더라도, 어떤 후회나 원 
망, 그리고 가지기 어려운 새로운 대안에 대한 열망을 가질 수 있음을 알 수 있었다. 전환장벽 에 대한 많은 연구들이 있었지만, 대다수의 연구 들이 소비자들의 전환의도를 낮춤으로써 기업의 고객으로 남게 하는 부분을 강조하는 기업 시각 이 반영되고 있다. 그러나 본 연구는 소비자의 심리적 부분에서 전환장벽이 부정적일 수 있음 을 밝힘으로써 소비자 시각에서 전환장벽의 영 향을 확장하고 있다는 이론적 시사점을 가진다.

셋째, 심리적 반작용이론이 일부 마케팅 분야 에 적용되었지만, 대부분의 연구가 커뮤니케이 션과 관련된 부분에 제한되어 있다. 본 연구는 전환이라는 상황에 심리적 반작용이론을 적용 함으로써 심리적 반작용이론의 마케팅 분야 연 구의 확장 가능성을 넓혔다는 데 그 의의가 있 을 것이다.

또한 이 연구는 다음과 같은 실무적 시사점을 가진다.

첫째, 본 연구의 결과에 의하면, 다른 매력적 인 대안으로 못가게 하려고 만든 전환장벽이 오 히려, 현재 제공자를 선택했던 것을 후회하게 하고, 현재 제공자를 원망하게 할 수 있으며, 전환하지 못하게 된 제공자를 더 갈망하게 만 드는 결과를 낳을 수 있다는 것이다. 이는 당장 은 해당 기업과의 관계를 유지할 지라도 결국 에 기업 수익에 부정적 영향을 주는 미래 행동 을 분명히 이끌 것임을 암시한다. 즉 전환장벽 을 이용해 다른 매력적인 대안으로의 전환을 막는 것은 임시방편에 불과하며, 단순히 전환장 벽으로 묶어두고 안도하는 것을 기업이 경계해 야 함을 시사하고 있다.

둘째, 연구에서 발견된 전환 장벽의 심각성이 부정적 반응에 주는 영향 역시 실무적으로 시
사하는 바가 있다. 더 강하게 전환 장벽을 만드 는 것이 더 소비자들의 심적으로 튕겨나가게 하는 역할을 할 수도 있기 때문에, 소비자들이 외적인 압력에 의해서 심각하게 제재 받았다는 생각이 들지 않도록 만드는 전랴을 구사해야 할 것이다. 예를 들어 자연스럽게 창출되는 전 환장벽(e.g., 탐색 비용)이나 고객 스스로(e.g., 관계적 효용) 만들어내는 전환장벽은 수용가능 하다고 지각되므로(Egan 2001), 강압적인 장벽 (e.g., 재무적 전환 비용)보다는 이러한 장벽들 을 활용하는 것이 강제적이라는 느낌이 덜 들 고 그에 따라 전환장벽에 대한 부정적 반응의 발생을 막을 수 있을 것이다.

셋째, 상호작용 공정성은 전환이 좌절된 상황 에서도 실패상황과 유사하게 긍정적 역할을 함 을 알 수 있었다. 현재 많은 서비스 기업들의 실수중 하나가 잡은 물고기에게는 먹이를 잘 주지 않는다는 것이다. 왜냐하면 처음에 설정한 전환장벽이 있음으로 인해, 맛있는 먹이를 많이 주지 않아도, 심지어는 불만족한 경우라도 전환 하지 않는다고 믿기 때문이다. 하지만, 본 연구 에 의하면 전환장벽의 존재만으로도 충분히 부 정적 심리 반응을 일으킬 수 있기 때문에, 이를 경감시키는 노력이 요구되며, 이때 중요한 부분 이 친절함과 같은 인간적인 대우 일 것이다.

\section{3 연구의 한계점과 미래연구제안}

첫째, 본 연구는 전환장벽에 대한 새로운 시 각을 구체화한다는 데 의의가 있지만, 이와 관 련한 초기 연구이기 때문에 비교적 다양한 변 수들이 고려되지 않았다는 한계점을 가진다. 이 런 이유에서 좀 더 다양한 측면에서 좌절상황 
의 특성을 제시한다거나 혹은 부정적 심리반응 뿐 아니라 어떤 다양한 방향의 반응들로 확장 해서 살펴볼 필요가 있다.

둘째, 상호작용 공정성을 제외하고는, 지각된 공정성이라는 조절변수의 역할이 명확하게 검 증되지 않았다. 이는 앞서 설명한 결과변수가 심리적 부분이라는 이유 때문일 수 있지만, 조 직연구에서 사용한 측정도구를 수정해 이용했 기 때문일 가능성도 있다. 따라서 측정도구를 조직 구성원이 아닌 고객 측면에 더 가깝게 수 정해서 사용한다면 좀 더 정확한 결과를 얻을 가능성이 있기 때문에 차후 연구에는 이를 반 영해야 할 것이다.

셋째, 본 연구는 전환장벽의 부정적 영향을 설명하기 위해 심리적 반작용이론에 근거하고 있기 때문에, 구체적인 어떤 전환장벽에 초점을 두기 보다는 일반적인 어려움이라는 측면에서 장벽에 접근하고 있다. 차후에는 단순히 장벽을 어려움이라는 측면에서가 아니라. 구체적으로 어떤 장벽들이 심리적 반작용과 더 연관될 수 있는지에 관한 연구가 필요할 것이다. 구체적인 장벽들이 부정적 결과에 어떤 영향을 주는 지 밝힌다면 더 깊이 있는 이론적 실무적 시사점 의 도출이 가능할 것이다.

넷째, 전환좌절 상황에서의 반응의 측정에 있 어 응답자의 기억에 의존하고 있기 때문에, 감 정 측정 시점의 차이로 인한 외생변수가 개입 되었을 가능성이 있다. 차후 연구에서는 이런 부분들을 개선하여 좀 더 정확한 결과를 이끌 필요가 있다.

〈논문 접수일: 2012. 01. 12〉 〈1차 수정일: 2012. 04. 10〉 〈게재 확정일: 2012, 04. 12〉

\section{참고문헌}

박미영, 박정은, 이성호 (2010), "고객시민행동 의 주요 선행 및 결과 변수에 관한 연구: 기업과 고객 간의 장기지향성에 미치는 영 향을 중심으로" 한국마케팅저널, 11(4), 1-19. 박상언 (2009), "감정부조화의 영향과 그 조절요 인에 관한 실증연구: 직무자율성과 사회적 지원의 조절효과를 중심으로," 경영학연구, 38(2), 379-405.

윤만희 (2003), "대학교육서비스에 대한 공정성 인식이 관계품질과 고객의 자발적 행위에 미치는 영향," 경영학연구, 32(1), 315-340. 정윤희, 이종호 (2010), "경험적 소비에서 장벽 과 그 영향에 관한 연구 -접근가능성과 접 근동인을 통한 이중적 영향을 중심으로-," 한국심리학회:소비자-광고, 11(2), 375-406. 차재호, 구자숙 (1999), “사회적 시나리오를 찾 기 위한 예비 연구: 관계감정을 느끼게 하 는 상황의 탐구," 한국심리학회: 사회및성 격, 13(1), 203-217.

Adams, J. S. (1965), "Inequity in Social Exchange", In L. Berkowitz(Ed), Advances in Experimental Social Psychology (pp 267299), New York: Academic Press.

Aiken, L S. and West, S. G. (1991), Multiple Regression: Testing and Interpreting Interactions, Beverly Hills, CA: Sage.

Anderson, James C. and Narus, J. A. (1990), "A Model of Distributor Firm and Manufacturer Firm Working Partnerships," Journal of Marketing, 54(1), 42-58. 
Berkowitz, L. (1990), "On the Formation and Regulation of Anger and Aggression: A Cognitive Neoassociationistic Analysis," American Psychologist, 45, 494-503.

Bies, Robert J. and Joseph S. Moag (1986), "Interactional Justice: Communication Criteria of Fairness," in Research on Negotiation in Organizations, (Vol. 1, 43-55), Greenwich, CT: JAI Press.

Blodgett, J. G., Granbois, D. H., and Walters, R. G. (1993), "The Effects of Perceived Justice on Complainants' Negative Wordof-Mouth Behavior and Repatronage Intentions," Journal of Retailing, 69(4), 399428.

Bohn, M. J., Krahn, D. D., and Stachler, B. B. (1995), "Development and Intial Validation of a measure of Drinking Urges in Abstinent Alcoholics," Alcohol Clin Exp Res, 19, 600-606.

Brehm, Jack W. (1966), A Theory of Psychological Reactance, New York: Academic Press, Inc.

, Stires, L. K. Sensenig, J., and Shaban, J. (1966), "The Attractiveness of an Eliminated Choice Alternative," Journal of Personality and Social Psychology, 2, 301313.

(1972), Response to Loss of Freedom:

A Theory of Psychological Reactance, Morristown, NJ: General Leaming Press. and Brehm, S. S. (1981), Psychological Reactance: A Theory of Freedom and
Control, San Diego, CA: Academic Press. Burnham, T. A., and Frels, J. K., and Mahajan, V. (2003), "Consumer Switching Costs: A Typology, Antecedents, and Consequences," Journal of the Academy of Marketing Science, 31(2), 109-126.

Colgate M, and Lang B. (2001), "Switching Barriers in Consumer Markets: An Investigation of the Financial Services Industry," Journal of Consumer Marketing, 18(4): 332-347.

Clee, Mona A. and Robert A. Wicklund (1980), "Consumer Behavior and Psychological Reactance," Journal of Consumer Research, 6 (March), 389-405.

Clemmer, Elizabeth C. (1993), "An Investigation into the Relationships of Justice and Customer Satisfaction with Services," in Justice in the Workplaces: Approaching Fairness in Human Resources Management, $R$. Cropanzano, ed, New York: Lawrence Erlbaum, 193-207.

Dillard, J. P., and Shen, L. (2005), "On the Nature of Reactance and its Role in Persuasive Health Communication," Communication Monographs, 72, 144-168.

Egan J. (2001). Relationship Marketing. Exploring Relational Strategies in Marketing. Financial Times/Prentice Hall; 1st ed edition (May) Folger, E. and Konovsky, M. (1989), "Effects of Procedural and Distributive Justice on Reactions to Pay Raise Decision," Academy of Management Journal, 31, 115-130. 
Frijda, Nico H., Peter Kuipers, and Elisabeth ter Schure (1989), "Relations among Emotion, Appraisal, and Emotional Action Readiness," Journal of Personality and Social Psychology, 57(2), 212-228.

Glovich, Thomas and Victoria Husted Medver (1995), "The Experience of Regret: What, When, and Why," Psychological Review, 102, 379-395.

Hammock, Thomas and Jack W. Brehm (1966), "The Attractiveness of Choice Altematives When Freedom to Choose is Eliminated by a Social Agent," Journal of Personality, 34, 546-554.

Henion, K. E., and Batsell, R. R. (1976), "Marketing of Blood Donorship, Helping Behavior and Psychological Reactance," In K. L. Bernhardt(Ed), Proceedings of the Educators' Conference of the American Marketing Association(Vol. 38, pp. 652-656), Chicago: American Marketing Association. Hess. R. L (2008), "The Impact of Firm Reputation and Failure Severity on Customers' Responses to Service Failures," Journal of Service Marketing, 22(5), 385-398.

Jones Thomas. O, and Sasser W. Earl, Jr. (1995), "Why Satisfied Customers Defect?," Harvard Business Review, 73(6), 89-99.

Jones, Michael A., David L. Mothersbaugh and Sharon E. Beatty (2000), "Switching Barriers and Repurchase Intentions in Services," Journal of Retailing, 76(2), 259-274.

Landman, J (1987), "Regret and Elation Fol- lowing Action and Inaction Affective $\mathrm{Re}^{-}$ sponses to Positive Versus Negative Outcomes," Personality and Social Psychology Bulletin, 13(4), 524-536.

(1993), Regret: The Persistence of the Passible, New York: Oxford University Press.

Lemerise, E. A., and Dodge, K. A. (1993), "The Development of Anger and Hostile Interactions," In $M$. Lewis \& J. M. Haviland(Eds), Handbook of Emotions(pp. 537-546). New York : Guilford.

Lewin, K. (1935), A Dynamic Theory of Personality, New York: McGraw-Hill

Lind, E. Allan and Tyler, T. R. (1998), The Social Psychology of Procedural Justice, New York: Plenum Press.

Masterson, S. S., Lewis, K., Goldman, B. M., and Taylor, M. S. (2000), "Integrating Justice and Social Exchange: The Differing Effects of Fair Procedures and Treatment on Work Relationship," Academy of Management Journal, 43, 738-738.

Mazis, Michael. B., Robert B. Settle, and Dennis C. Leslie (1973), "Elimination of Phosphate Detergents and Psychological Reactance," Journal of Marketing Research, 10(4), 390-395.

Mowen, John C. (1992), "The Time and Outcome Valuation Model: Implications for Understanding Reactance and Risky Choices in Consumer Decision Making," Advances in Consumer Research, 19, 182-189. 
Ohanian, R. (1990), "Construction and Valuation of a Scale to Measure Celebrity Endorsers' Perceived Expertise, Trustworthiness, and Attractiveness," Journal of Advertising, 19 (3), 39-52.

Oliva T A, Oliver R I., MacMillan I C. (1992), "A Catastrophe Model for Developing Service Satisfaction Strategies." Journal of Marketing, 56(July): 83-95.

Oliver, Richard L, and Wayne S. DeSarbo (1988), "Response Determinants in Satisfaction Judgments," Journal of Consumer Research, 14(March): 495-507.

Reeve, J. (2005), Understanding Motivation and Emotion(4th ed). Hoboken, NJ: Wiley.

Rutte, C. and Messick, D. (1995), "An Integrated Model of Perceived Unfairness in Organization," Social Justice Research, 8 (3), 239-261.
Tax, Stephen S., Stephen W. Brown, and Murali Chandrashekaran (1998), "Customer Evaluations of Service Recovery Experiences: Implications for Relationship Marketing," Journal of Marketing, 62(Apr), 60-76.

Zeelenberg. Marcel and Rik Pieters (1999), "Comparing Service Delivery to What might have been: Behavioral Responses to Disappointment and Regret," Journal of Service Research, 2, 86-97.

Zeelenberg, Marcel, Wilco W. van Dijk and Antony S. R. Manstead (2000), "Regret and Responsibility Resolved? Evaluating Ordonez and Connolly's(2000) Conclusions," Organizational Behavior and Human Decision Processes, 81, 143-154. 


\section{〈부록〉 붙임 1. 변수의 설문문}

- 전환 좌절된 대안의 매력성:

1 내가 전환하고 싶었던 새로운 000 기업은 매력적이었다.

2 내가 전환하려 했던 새로운 000 기업은 현재 기업보다 나은 혜택을 제안했었다.

3 나는 새로운 000 기업에 마음이 끌렸다.

- 전환을 좌절시킨 장벽의 심각성:

1 전환을 못하게 만들었던 어려움은 강력했다.

2 현재 거래중인 기업을 새로운 000 기업으로 바꾸는 것에 대해 강하게 제약받았다.

3 전환을 못하게 만들었던 어려움은 내가 통제하기 힙든 것이었다.

- 이전 선택에 대한 후회:

1 나는 현재 거래하는 이 기업을 선택한 것을 후희한다.

2 나는 이 기업을 선택한 것을 유감스럽게 느낀다.

3 현재 거래 중인 이 기업을 선택한 것은 잘못된 것이다.

- 현재 제공자에 대한 원망:

1 나는 현재 거래하는 이 기업이 원망스럽다.

2 나는 현재 거래하는 이 기업이 밉다.

3 나는 현재 거래하는 이 기업이 고맙다. (역코딩 항목)

- 좌절된 제공자에 대한 열망:

1. 내가 지금 간절히 원하는 것은 전환하지 못하게 된 000 기업과의 거래다.

2 나는 000 기업과의 거래를 정말로 원한다.

3 지금 000 기업으로 전환하는 것보다 더 바라는 일은 없다.

- 결과 공정성:

1 현재 기업은 나에게 전반적으로 공정한 결과물(예를 들어 로열티 프로그램 혜택, 서비스 제공물 등) 을 주었다.

2 지금까지 이 기업과 했던 거래에 비춰볼 때, 이 기업은 나에게 공정한 제공물을 주었다.

3 내가 이 기업과 거래하기 위해 희생한 것들(예를 들어 노력이나 시간, 다른 제공자와의 거래의 포 기)에 비추어 볼 때, 공정한 보상을 해주었다.

4 내가 이 기업의 성과에 기여한 바를 고려할 때, 이 기업이 나에게 제공한 제공물은 공정하다.

- 절차 공정성:

1 현재 기업은 지금까지 어떤 문제든 빠르고 공정하게 처리해주었다.

2 이 기업은 정확하고 적절한 자료를 통해 나에게 주는 제공물을 결정하고 있다.

3 나에게 주는 혜택의 결정은 일관된 기준에 따라 이루어졌다.

- 상호작용 공정성:

1 이 기업은 전반적으로 나에게 친절하게 대해 주었다.

2 이 기업은 평소에 내가 가진 개인적 욕구를 잘 고려해 주었다.

3 이 기업의 직원들은 나를 친절하고 인격적으로 대우해 주었다. 


\title{
The Effects of Switching-Frustrated Situation on Negative Psychological Response
}

Jeong, Yun $\mathrm{Hee}^{*}$

\begin{abstract}
Despite the voluminous research on switching barriers, the notion that they can generate negative responses has not been investigated. Further, a critical question is what determines the strength of such negative responses. To address this question, the classic theory of psychological reactance is briefly reviewed, and the idea of switching barrier is advanced.

This study attempts to suggest a model on the negative effects of switching- frustrated situation, based on the studies on psychological reactance. According to psychological reactance theory (Brehm 1966), whenever a freedom is threatened or removed, individuals are motivated, at least temporarily, to restore their freedom. For example, if individuals think they are free to engage in behaviors .v, y. or $z$, then threatening their freedom to engage in $\mathrm{x}$ would cause psychological reactance. This reactance could be reduced by an increase in the perceived attractiveness of engaging in, the threatened behavior(Kivetz 2005).

This investigation seeks to extend existing switching barrier research in three important ways. First, while the past research has emphasized only positive role of switching barrier, this study address negative role of it by applying psychological reactance theory.

Second, to find negative results of switching barrier, I suggest negative psychological response including regret to the past choice, resentment to the present provider, and strong desire to the alternative provider.

Third, I suggest the perceived severity of the switching barriers, the attractiveness of the alternative as switching-frustrated situation which can lead to negative results. And, in addition to these relationships, I added moderated effects of perceived justice for better explanation. So this study includes the following hypotheses.

H1-1 H1-3: The attractiveness of the alternative has a positive effect regret to the past choice (h1-1), resentment to the present provider (h1-2), and strong desire to the alternative provider (hl-3). H2-1 H2-3 : The perceived severity of the switching barrier has a positive effect regret to the past choice (h2-1), resentment to the present provider (h2-2), and strong desire to the alternative

\footnotetext{
* Assistant Professor, Department of Business Administration, Konkuk University.
} 
provider (h2-3). H3-1 H3-3 : The positive relationships between the attractiveness of the alternative and consumer' negative responses will be stronger at low level of perceived justice than at high level of perceived justice. H4-1 H4-3 : The positive relationships between the perceived severity of the switching barrier and consumer' negative responses will be stronger at low level of perceived justice than at high level of perceived justice.

Survey research is employed to test hypotheses involving perceived severity of the switching barrier(Hess 2008), attractiveness of the alternative(Anderson and Narus 1990: Ohanian 1990), regret(Glovich and Medvec 1995), resentment, strong desire(Alcohol Urge Questionaire: Bohn et al. 1995), perceived justice(Bies and Moag 1986: Clemmer 1993: Lind and Tyler 1998). Previous researches, such as reactance theory, emotion and service failure, have been referenced to measure constructs. All items were measured on a 7-point Likert scale ranging from "strongly disagree" to "strongly agree". We collected data involving various service field, and used 249 respondents to analyze these data using the moderated regression.

The results of our analysis suggest, as expected, that the perceived severity of the switching barrier had positive effects on regret to the past choice $(b=.197, p<.01)$, resentment to the present $\operatorname{provider}(b=.214, p<.01)$, and strong desire to the alternative provider $(b=.254, p<.001)$. And the attractiveness of the alternative had positive effects on regret to the past choice $(b=.353, p<$ $.001)$, resentment to the present $\operatorname{provider}(b=.174, p<.01)$, and strong desire to the alternative provider $(b=.265, p<.001)$. However, our findings indicate perceived justice partly moderates relationship between switching-frustrated situation and psychological negative response.

The study has brought to light a number of insights between switching barriers and consumer' negative responses that have been subject to little prior research. In particular, this study adds to the existing understanding of the psychological responses to switching barriers in switching- frustrated situation.

This research therefore has significance to marketers for strategic marketing programs, particularly in terms of customer retention and switching barrier strategies. Since consumers could exhibit negative responses to switching barrier, companies would be able to lose their customer when they thoughtlessly use switching barrier for remaining customer.

Although the study has these contributions, there are several limitations including unsupported hypotheses and research method. So, we need to make up for these limitations in the future researches.

Key words: Switching-frustrated situation, Switching barrier, Regret, Resentment, Strong desire, Perceived justice. 